\title{
How to deal with sociocultural pressures in daily life: reflections of adolescent girls suffering from eating disorders
}

This article was published in the following Dove Press journal:

Journal of Multidisciplinary Healthcare

16 April 201 I

Number of times this article has been viewed

\section{Sanna Aila Gustafsson' \\ Birgitta Edlund ${ }^{2}$ \\ Josefine Davén' \\ Lars Kjellin' \\ Claes Norring ${ }^{3}$}

'Psychiatric Research Centre, Örebro University, School of Health and Medical Sciences, Örebro, Sweden; ${ }^{2}$ Department of Public Health and Caring Sciences, University of Uppsala, Uppsala, Sweden; ${ }^{3}$ Center for Psychiatry Research, Karolinska Institute, and Stockholm Center for Eating Disorders, Stockholm, Sweden

Correspondence: Sanna Aila Gustafsson Psychiatric Research Centre, PO Box 1613, S-70116 Örebro, Sweden $\mathrm{Tel}+46722495986$

Fax +46 196025886

Email sanna.aila-gustafsson@orebroll.se
Abstract: Adolescent girls with eating disorders experience unattainable and contradictory expectations in daily life, which create stress and negatively affect their self-evaluation. Disordered eating may function as a way of seeking control and consistency. In order to make progress in the understanding of eating disorders, the aim of this study was to describe how adolescent girls with eating disorders reflect upon ways of dealing with sociocultural pressures in daily life. Eighteen interviews with girls aged 15-19 years were analyzed using a phenomenographic approach. The results were summarized into three conceptions: "Striving to be oneself" (conception A) was described as the most desirable, but also the hardest. "Adapting to various situations" (conception B) was used without much reflection, as long as it worked, but when this way of dealing with everyday expectations was unsuccessful it was evaluated negatively. "Presenting oneself in a positive light" (conception C) was described negatively even when it was successful. Within these conceptions, the participants described various strategies that could be used more or less effectively depending on the circumstances. A common theme was their difficulties in finding a balance between trying harder to live up to perceived expectations from others on one hand, and trying to accept the situation as it was, without trying to change themselves or the situation, on the other hand. The participants believed that their eating disorder was partly a result of being unable to deal with sociocultural pressures in an effective way, and they experienced a conflict between societal values of being assertive and values of being interpersonally oriented. Implications for treatment are discussed.

Keywords: mental health, qualitative, phenomenography

\section{Introduction}

Eating disorders affect as many as $10 \%$ of adolescent girls and are associated with significant adverse medical and psychological consequences. ${ }^{1}$ These conditions were earlier considered Western phenomena, but as a consequence of a more global culture they are now seen all over the world in all social and cultural contexts. ${ }^{2}$ Eating disorders have been described as means of seeking control and consistency when life feels overwhelming. ${ }^{3,4}$ In an interview-based study, patients with anorexia nervosa described how their eating disorder gave them an inner feeling of drive, mastery, identity, and self-confidence, and how it helped them to obtain a sense of stability and security and to avoid negative emotions and experiences. Some of them also described their eating disorder as a means of communicating difficulties and eliciting care from other people..$^{5}$ It thus seems like disordered eating may serve important purposes in times of distress. 
Adolescence is a time characterized by added preoccupation with image and concern with social acceptance. For adolescents whose self-evaluation is closely related to success and achievement instead of inner qualities, a fear of negative evaluation may prohibit discussing their problems with others and constrain effective and flexible coping. ${ }^{6}$ Adolescent girls with an eating disorder experience many unattainable and contradictory expectations in daily life, which create stress and negatively affect their self-evaluations. ${ }^{7,8}$ In a study by Mussap, ${ }^{9}$ the pressure to conform to feminine gender stereotypes was found to be associated with unhealthy body change strategies in women. Social pressures from mass media, family, and peers have been shown to encourage social comparisons, internalization of a thinness ideal, over-emphasis on the importance of appearance, and body dissatisfaction in adolescent girls. ${ }^{10}$ However, adolescent girls are negatively affected not only by their exposure to social expectations but also by their own ways of dealing with these expectations. It has been shown that recurring distressing experiences and conditions in daily life affect psychological health more negatively than isolated adverse life events. The more these recurring experiences become internalized within the individual's value system, the more they influence psychological wellbeing. ${ }^{11}$

In a previous study it was found that the participants internalized various expectations about how an adolescent girl should look, perform and behave. These perceived expectations were often contradictory, and the participants experienced considerable stress about how to balance between them. ${ }^{8}$ Previous research has found that internalized cultural values, which prescribe or inhibit certain types of actions or feelings, may prevent girls and women from dealing with sociocultural pressures in a more assertive way. ${ }^{6,12}$ Stress may stimulate disordered eating in individuals with initial body dissatisfaction, ${ }^{13}$ and disordered eating may acquire a functional status by reinforcement ${ }^{14}$ so that a person gets stuck in a spiral of using disordered eating to regulate negative emotions and stressful experiences.

Consequently, sociocultural pressures concerning appearance, behavior, and performance are likely to be daily influences that impact powerfully on adolescent girls. However, empirical studies on how patients with eating disorders deal with sociocultural pressures in daily life are scarce. Despite the fact that eating disorders are highly gendered conditions, the bulk of eating disorder research does not address gender inequality and its impact and expression in girls' social environments. ${ }^{15}$ An eating disorder is a social disease which needs to be understood within the sociocultural context, and to make progress in the understanding of eating disorders it has been suggested that we need to broaden our view to a more social-psychological perspective. ${ }^{16}$ Knowledge about how girls with eating disorders deal with their daily experiences could be essential within therapeutic meetings. Thus, the aim of this study was to describe how adolescent girls with eating disorders reflect upon ways of dealing with sociocultural pressures in daily life.

\section{Methods}

\section{Participants and procedure}

Data for this study were obtained from interviews with girls who had been accepted for treatment at an out-patient unit at a specialized eating disorder service in Sweden. A total of 31 girls were asked to participate in the study, and 18 of them accepted. Participants were between the ages of 15 and 19 years, and all of them were diagnosed with an eating disorder according to the Diagnostic and Statistic Manual of Mental Disorders (DSM-IV) ${ }^{17}$ Eating disorders can be divided into three main categories: anorexia nervosa (AN), bulimia nervosa $(\mathrm{BN})$ and eating disorders not otherwise specified (EDNOS), which in turn are sub-typed into six categories. ${ }^{17}$ Eight of the participants had restrictive eating disorder pathology. Of these, five were diagnosed with AN, and another three with sub-threshold AN (EDNOS type 1 or type 2). Six participants reported binge eating. Of these, one was diagnosed with $\mathrm{BN}$, and five with sub-threshold BN (EDNOS type 3). The remaining four participants were girls of normal weight who frequently purged after eating normal amounts of food as a means of weight control (EDNOS type 4).

Ten of the girls were living with both parents, five alternated between living with their mother and their father, one was living with an older sister, and two were living with their boyfriends. Nine of the girls were living in a Swedish middle-sized city (population 132,277), and the remaining girls were living in smaller towns or in the countryside. Four of the girls were still in high school, and the remaining girls represented a broad range of higher education. One girl had immigrated to Sweden and another had parents who had immigrated to Sweden.

A purposeful selection was made to ensure a variety of diagnoses, ages, living conditions, school backgrounds, and interests. The girls were given verbal and written information about the study. The first author contacted the girls who agreed to take part in the study, and an appointment was made at a time and place that suited the girl. Seventeen of the interviews took place at the eating disorder unit, and 
one in the girl's home. The first author conducted all the interviews, each lasting 35-65 minutes. Each interview was tape-recorded and transcribed verbatim. The inclusion period was between November 2006 and March 2008. The Regional Ethical Review Board at Uppsala University, granted approval for the study.

Originally, the focus of the interviews was on participants' perceptions and how they were affected by expectations in their daily lives. A checklist was used to ensure that important topics were covered, and the participants were encouraged to speak freely about each topic. In doing so the girls spontaneously began to reflect upon various ways of dealing with sociocultural pressures. Therefore this study was divided into two. One study focused on the participants' perceptions of expectations in daily life, ${ }^{8}$ and the present study focusing on the participants' reflections on how to deal with these sociocultural pressures.

\section{Data analysis}

A phenomenographic research approach was used. Phenomenography is a context-related approach in which the differences between people's ways of experiencing and perceiving their worlds are brought into focus of awareness. Thus, the results of a phenomenographic study lie in the variation of people's experiences. Focus is then upon the way in which the studied phenomenon is perceived (ie, second order perspective). The purpose of a phenomenographic study is to describe the critical aspects of a person's way of experiencing the world that enables them to handle it more or less effectively. According to phenomenography, every phenomenon or situation that a person encounters may be understood in a limited number of qualitatively distinct ways. These are represented by different conceptions of the phenomenon. The results of a phenomenographic study consists of the various conceptions and the relations between them. This is known as the outcome space. ${ }^{18}$ In phenomenography, it is assumed that in order to make sense of how people handle specific situations we need to understand the various ways in which they conceptualize them. ${ }^{19}$ Since we were interested in capturing the variation in the participants' perceptions, we chose a phenomenographic research approach.

In the first step of the data analysis, statements concerning ways of dealing with sociocultural pressures in daily life were identified and coded in an open coding in QSR N'Vivo, version $8 .{ }^{20}$ This was carried out by the first author.

In the second step, these statements were compared in terms of similarities, differences, and complementarities in the participants' statements to find distinct ways of describing thoughts and reflections about how to deal with these pressuring expectations. In this step, two of the authors (SAG and JD) independently grouped the statements.

In the third step, these preliminary groups were discussed and compared in a process of negotiated consensus. ${ }^{21}$ Similar statements were grouped together, and a preliminary map of the outcome space was obtained.

In the final step, each statement was discussed and grouped in relation to the outcome space. This process resulted in descriptions of the unique character of each conception and the relations between them.

The results are presented with citations that clarify the specific character of each conception. Brackets enclosing three dots (ie, [...]) indicates that words have been removed, while three dots in the text (ie, ...) indicates a pause in the participant's speech. The names of the participants have been changed to protect their privacy.

\section{Findings}

All of the participants experienced difficulties in dealing with sociocultural pressures effectively, and nearly all of them believed that their eating disorder was at least partly a result of these difficulties. Several described how, once their eating disorder had become established, they used it to reduce anxiety and create a feeling of control.

If you've failed in something [...] then it felt good to sort of, yeah it could feel good not to eat that sandwich or something. It kind of evened things out in a way (Tina, 16 years)

I didn't feel comfortable and so I wanted to get that secure feeling back again, so I cut down on food [...] I noticed that I was getting thinner, and I thought it looked good, so I figured I could cut down a bit more because then I'll maybe look even better. And so it went on until I was at a level where I didn't have the strength any more because I wasn't getting enough food (Fredrika, 17 years).

The participants described three qualitatively different conceptions of dealing with everyday expectations. Conception A regarded striving to be oneself, conception B had to do with adapting to various situations, and conception $\mathrm{C}$ involved presenting oneself in a positive light. Most of the participants made use of all three strategies, but in varying degrees and with variable success. Conception A was described by the participants as the most desirable, but also the hardest. Conception B was not given a positive or negative evaluation as long as it worked, but when it did not work the participants described this way of relating negatively. 
Conception $\mathrm{C}$ was described in a negative way, as being weak, false, or immature and not daring to be oneself. Within these conceptions, the participants described various strategies that could be used more or less effectively depending on the circumstances. A common theme that could be seen in all these conceptions was the participants' difficulties in finding a balance between dealing with these everyday expectations by strategies aiming at changing themselves or the situation, and strategies aiming at accepting themselves and the situation as it was.

\section{Conception A: striving to be oneself}

The participants described conception A as striving to accept themselves with both their weaknesses and strengths and to think and act according to the premise that they were good enough as they were. This meant standing for who they were without pretence, setting themselves realistic goals, daring to say what they felt, and marking boundaries towards others if they felt that their own needs or wishes were in conflict with those of others. This was described to require a concerted and conscious effort.

It's about being oneself, and that's not easy. It's not easy to know who one is and that. Yeah, I don't really know how you should do it, but you know, you have to try according to how you're feeling, and you have to try not to think too much about what you're like. [...] I think if you're a bit unsure of yourself, and it's easy to be, then it's hard. It's as though you lose yourself and then it's difficult to be honest, and be oneself [...] I think the most important thing is that you, like, find yourself and can stand up for yourself and relax in it and that. Feel secure in yourself and trust yourself, then I think you manage most things and it feels good. [...] I want to be able to say what I feel and set limits and not conform to every little thing, every new person I meet - I don't want to change into a new person (Tina, 16 years).

\section{Conception B: adapting to various situations}

Conception $\mathrm{B}$ had to do with fitting in by adapting oneself to the situation one was in and avoiding sticking out or coming into conflict with others. The participants tried to find a way of relating in which they would not rub others up the wrong way but in which they could still stand up for their own behavior. They tried to consider how their behavior affected other people. One way of doing this was to put aside their own needs, if they felt that this would give the best outcome for someone else or several of those in the group, even if this cost a lot of energy.
If there's something I really, really don't want and not everyone would do, then I'd say no. [...] But if there are some friends who ask if I'm going to a party and everyone's going, then I'll go along even if I don't really feel like it. Because you want to be there if everyone's going to be there. Maybe something will happen that everyone will talk about and yeah. [...] You want to fit in and that (Celia, 16 years).

\section{Conception C: presenting oneself in a positive light}

Conception $\mathrm{C}$ was about presenting oneself positively and hiding characteristics or qualities that could prompt criticism. This meant largely being happy, making an effort to look good, and giving the impression that one succeeded with things. The participants evaluated these strategies negatively. Yet all of the participants described several situations in which they used strategies in conception $\mathrm{C}$, and many described how these strategies worked well in certain situations.

It was for my own sake or because I wanted to feel I looked good when I saw myself in the mirror and yeah, feel that I ... [...] If it's one of those days when you don't feel so great and you're just cranky and that, then you can think, "what if they never call me again" and you're scared you won't be allowed to be with them [...] It's better to be happy so you don't have to answer any awkward questions (Irene, 16 years).

[...] You can't be down one day, you have to be happy all the time and open and positive and everything. Even if you aren't feeling happy that day, you still have to run around being positive. [...] It's like all your energy goes into being happy at school, so you have to be a bit cranky when you get home (Celia, 16 years).

\section{Common theme: finding the right balance between acceptance and change}

A common theme seen in all three conceptions was the participants' difficulties in finding a balance between acceptance and change. This pattern seemed to interfere with effective coping regardless of whether the participant's objective was to be herself, to adapt to others expectations, or to present herself in a positive light. On one hand the participants felt that they should try to change themselves or the situation in order to fulfill their own or others' expectations on them, but on the other hand they felt that they should accept that there were expectations that they could not or did not wish to fulfill. This often resulted in a situation where they struggled really hard to achieve something, and although they initially 
succeeded, instead of feeling satisfied with themselves they felt that this only increased the expectations and they had to try even harder to reach an even higher level in the future.

It gets more and more intense. Like it never ends. It's like, well, she managed that so we take it a bit higher, and then you manage that and then it goes a bit higher still. Like, it's like that with everything - with work and everything. Everything is about climbing higher and higher: be prettier, be thinner, be better, manage more. I think it's like that with everything, like if you've managed one thing then here's something else. [...] If I manage to reach a goal, then I'm happy for a while but then I get some new demand and the whole thing crumbles (Petra, 18 years).

Eventually the standards were set so high that the participants inevitably failed to live up to these perceived expectations, and then they were afraid to try again because they were afraid of failing again. When they reached a point where they could no longer change themselves or the situation to fulfill these high expectations, they described that they gave up and felt like failures.

I always give a hundred percent in everything I do but if it doesn't hold then I just get angry with myself and unsure of myself. [...] In the end you just give up. Either I fight really hard to get it just perfect or I give up (Linda, 18 years).

In some situations, the participants felt discouraged from some options, based on their gender:

If you're good at your sport for your sex, well, a guy can aim to be a pro and earn millions, but if a girl trains that much, she still has to have a job as well. So you limit yourself before you start so you won't be disappointed because you know what reality looks like (Jonna, 18 years).

Thus, regardless of whether they used strategies from conception A (striving to be oneself), conception B (adapting to various situations), or conception $\mathrm{C}$ (presenting oneself in a positive light), they appeared to struggle with these contradicting sociocultural pressures and with finding the right balance between different strategies to deal with them.

\section{Discussion}

The participants described three qualitatively different conceptions of dealing with sociocultural pressures in daily life. These three conceptions can be hierarchically ordered according to how desirable the participants felt that they were. Conception A (striving to be oneself) was described by the participants as the most desirable, but also the hardest.
Adapting to various situations (conception B) was regarded as obvious when it worked. However, none of the participants described an interpersonal orientation as being a resource. Instead, they noted when it did not work and they then viewed their consideration for others negatively. Trying to deal with perceived expectations by presenting oneself in a positive light (conception $\mathrm{C}$ ) was described in negative terms. However, all of the participants described situations in which this strategy was successful. For example adopting a particular appearance sometimes gave a feeling of control, and putting on a happy façade could achieve distraction from stressful or demanding thoughts or avoidance of difficult questions from others.

The participants had difficulties finding a balance between their wish to change themselves or the situation, and accepting that there are expectations that can't be met, or that we choose not to fulfill. They tended to initially struggle really hard to live up to perceived expectations from others, and they described that even if they succeeded, the pressure they felt did not diminish because the expectations upon them were then raised for the next time. When the standards eventually became too high, they described a fear of failing, which resulted in a tendency to avoid trying at all next time. This way of dealing with the situation was not interpreted as a plausible way of dealing with the situation, by accepting the situation and themselves as they were; instead they interpreted it as giving up, and they evaluated themselves negatively and as a failure.

Most participants described that their eating disorder contributed in the short term to reducing anxiety and giving a feeling of control. The participants struggled with balancing the three conceptions of dealing with sociocultural pressures described in this study. Many of the participants said they felt they should set firmer limits for those around them, lower their high demands, and accept themselves as they were. The feeling they had of being unable to do this contributed to feelings of guilt and negative self-evaluation, since their wish to be themselves conflicted with values of being interpersonally oriented and showing consideration of others. Girls with eating disorders have been described as having a strong need for approval from others, ${ }^{22}$ heightened social anxiety, and fear of negative evaluation, ${ }^{23}$ and an interpersonal style that focuses on others' needs and expectations. ${ }^{6,24}$ Regardless which idiom is used, there is consensus that adolescent girls with eating disorders have difficulties balancing between the needs of themselves versus the needs of others. Eating disorders have also been associated with perfectionistic self-presentation, which involves attempts to create a façade of perfection and concealing perceived weaknesses. ${ }^{6,25,26}$ Although presenting 
oneself in a positive light is a functional strategy in certain situations, individuals with eating disorders seems to use this strategy frequently as a means of avoiding criticism from others. ${ }^{6,25,26}$ In light of the above, it is understandable that balancing these conceptions of dealing with sociocultural pressures in daily life may pose particular challenges for girls with eating disorders, which needs to be addressed.

For example when Tina explains that not eating can even things out when she feels that she has failed in something, we suggest that the treatment needs to address contradictions and pressures in her daily life, and explore and discuss what functions the eating disorder fulfils and how to find other, less harmful ways to reduce stress. It may then be clear that interpersonal skills, such as readiness to adapt in order to find solutions that suit everyone, or choosing to show positive sides of oneself are also important resources, and they are necessary in both working relations and personal relationships.

A contradicting reality in daily lives of adolescent girls is that girls are fostered to be interpersonally oriented and sensitive to the needs and feelings of others, ${ }^{27,28}$ at the same time as women's more interpersonal manner of handling expectations has been considered less functional than men's more individualistic manner. ${ }^{29,21}$ For example, avoidant coping has been associated with eating disorders, ${ }^{30,31}$ but may be both creative and effective in situations in which one needs to save energy for dealing with other problems ${ }^{29}$ or in situations that are refractory to change. ${ }^{32}$ Thus, it may sometimes be a functional strategy to act in compliance with gendered expectations, since there are sociocultural forces that discourage women from pursuing some options..$^{33,34}$ For example, when Jonna limits herself and does not wholeheartedly invest in her sport, this is an effective way of dealing with the situation for her. She lowers her expectations and thereby reduces the pressure upon herself; she is less at risk of disappointment than if she was to invest fully and fail. But this is also an illustration of how gender stereotypical expectations influence people and make choices more or less functional. We mean that this situation should not be interpreted as an individual dysfunctional coping strategy, but should rather be addressed on a societal level. Piran ${ }^{15}$ argues that we need to address how social systems shape girls' and women's lives, and that expecting individuals to change without a corresponding change in their social environment is unethical. We argue that instead of viewing some strategies as less functional than others, focus should be upon which of the alternatives is functional in any particular context. In this way, important resources are the ability to evaluate and judge a situation, one's own needs and wishes, the needs and wishes of others, and the probable consequences of various behaviors and, from this, being able to consciously decide on a strategy.

It has been suggested that eating disorder therapies tend to overemphasize norms like autonomy and independence, and not pay enough attention to the value of relationships and respect for the needs of others, and that it might be more therapeutic to teach the patient to critically explore different social norms ${ }^{27}$ and be able to handle the contradictions between them. Dialectical behavior therapy (DBT) is especially designed to help patients with emotional regulation difficulties and to learn how to balance the contradictions in life. In DBT it is suggested that patients with emotional regulation difficulties need to learn how to balance between acceptance and change. The emphasis is on accepting that there are contradictions in life, and learning how to accept these contradictions in a dialectical process, and to learn flexible ways to deal with daily life encounters. ${ }^{35,36}$ For example, when Linda describes how she gets angry with herself when she doesn't live up to her high standards, a more dialectical approach might be to accept that she can't live up to these standards and focus on re-evaluating her standards. Although DBT was first designed for patients with borderline personality disorder, ${ }^{35}$ it has shown promising results for patients with $\mathrm{BN}^{37}$ as well as binge eating disorder. ${ }^{38}$ Thus, incorporating some guiding principles from DBT in regular cognitive behavioural therapy for patients with eating disorders might teach patients the skills to deal with these contradictions in life.

This study examines how adolescent girls with eating disorders reflect upon ways of dealing with sociocultural pressures in daily life. The extent to which these results may be applicable to other contexts will depend upon similarities and differences in those contexts, ${ }^{39}$ since daily life encounters differ between individuals and groups of individuals according to age, context, and the individual's appraisal of the situation. Adolescent girls with eating disorders share the same sociocultural context as adolescent girls without eating disorders, and the conceptions found in this study may thus be applicable even to adolescent girls without an eating disorder.

However, previous research has shown that girls with eating disorders are especially vulnerable to sociocultural pressures, ${ }^{34,40}$ and have a strong need for approval from others, ${ }^{22}$ which may result in trying too hard to adapt to various situations, and to conceal perceived weaknesses. ${ }^{25,26}$ Thus, what are specific for girls with eating disorders is not the sociocultural pressures they experience, or the strategies 
they use to deal with them, but rather the constant struggle when dealing with these sociocultural pressures, and their relentless strivings to find the right balance between conflicting, and sometimes mutually incompatible expectations.

To ensure that we had a rich and varied body of empirical material we used purposive selection. Since the interviews were not originally designed to explore how the participants deal with sociocultural pressures, but rather to look at their understanding of these expectations and pressures, the data are taken from our participants' spontaneous narratives. This may be both a strength and weakness of the study. One disadvantage is that the interviewer did not pose so many follow-up questions since this topic was not the focus of the interview. An advantage was that the interviewer did not have preconceived ideas and has not steered the participants. We have tried to be faithful to the data by not using any predefined categories, and the themes that we have identified were the result of discussion and consensus. We have thus ensured that the results are well supported by the empirical data, and quotations have been used to exemplify and clarify.

In summary, the results of this study stress three qualitatively distinct conceptions for dealing with sociocultural pressures in daily life of adolescent girls with an eating disorder. The participants tended to consider strategies for being oneself to be the most desirable. Strategies for adapting to various situations were taken for granted as long as they worked, and they were considered negative when they did not work, while strategies for presenting oneself in a positive light were evaluated most negatively. We believe that adolescent girls in general, and adolescent girls with eating disorders in particular, need guidance to evaluate a situation, the needs and wishes of themselves and others, and the probable consequences of various behaviors, in order to find a balance between change-oriented and acceptance-oriented strategies. Efforts to be oneself, adapt to various situations, and present oneself in a positive light may thus complement one another in a functional and flexible way.

\section{Disclosure}

The authors report no conflicts of interest in this work.

\section{References}

1. Agras WS. The consequences and costs of the eating disorders. Psychiatr Clin North Am. 2001;24(2):371-379.

2. Nasser M, Malson H. Beyond western dis/orders: thinness and selfstarvation of other-ed women. In: Malson H, Burns M, editors. Critical Feminist Approaches to Eating Dis/orders. New York: Routledge/ Taylor \& Francis Group; 2009:74-86.

3. Bruch H. The Golden Cage: The Enigma of Anorexia Nervosa. Cambridge, MA: Harvard University Press; 1978.
4. Budd G. Disordered eating: young women's search for control and connection. J Child Adolesc Psychiatr Nurs. 2007;20(2):96-106.

5. Nordbo RH, Espeset EM, Gulliksen KS, Skarderud F, Holte A. The meaning of self-starvation: qualitative study of patients' perception of anorexia nervosa. Int J Eat Disord. 2006;39(7):556-564.

6. Geller J, Cockell SJ, Goldner EM. Inhibited expression of negative emotions and interpersonal orientation in anorexia nervosa. Int J Eat Disord. 2000;28(1):8-19 [erratum Int J Eat Disord 2000;28(4):481].

7. Jones DC, Vigfusdottir TH, Lee Y. Body image and the appearance culture among adolescent girls and boys: an examination of friend conversation, peer criticism, appearance, appearance magazines, and the internalisation of appearance ideals. J Adolescent Res. 2004;19(3):323-339.

8. Gustafsson SA, Edlund B, Davén J, Kjellin L, Norring C. Perceived expectations in daily life among adolescent girls suffering from eating disorders: a phenomenographic study. Eat Disord. 2010;18(1):25-42.

9. Mussap AJ. The relationship between feminine gender role stress and disordered eating symptomatology in women. Stress Health. 2007; 23(5):343-348.

10. Stice E, Schupak-Neuberg E, Shaw HE, Stein RI. Relation of media exposure to eating disorder symptomatology: an examination of mediating mechanisms. J Abnorm Psychol. 1994;103(4):836-840.

11. Lazarus RS. Puzzles in the study of daily hassles. J Behav Med. 1984; 7(4):375-389.

12. Katzman MA. Getting the difference right: it's power not gender that matters. Eur Eat Disord Rev. 1997;5(2):71-74.

13. Sassaroli S, Ruggiero GM. The role of stress in the association between low self-esteem, perfectionism, and worry, and eating disorders. Int $J$ Eat Disord. 2005;37(2):135-141.

14. Troop NA. Eating disorders as coping strategies: a critique. Eur Eat Disord Rev. 1998;6:229-237.

15. Piran N. A femninist perspective on risk factor research and on the prevention of eating disorders. Eat Disord. 2010;18(3):183-198.

16. Hesse-Biber S, Leavy P, Quinn CE, Zoino J. The mass marketing of disordered eating and eating disorders: the social psychology of women, thinness and culture. Womens Stud Int Forum. 2006;29(2):208-224.

17. American Psychiatric Association. Diagnostic and Statistical Manual of Mental Disorders. 4th ed. Washington, DC: American Psychiatric Association; 1994.

18. Marton F, Booth S. Learning and Awareness. MahWah, New Jersey: Lawrence Erlbaum Associates; 1997.

19. Marton F, DallÀlba G, Beaty E. Conceptions of learning. Int J Educ Res. 1993;19:277-300.

20. QSR International Pty Ltd. QSR NVivo. Version 8. 2005.

21. Wahlström R, Dahlgren LO, Tomson G, Diwan VK, Beermann B. Changing primary care doctors' conceptions - a qualitative approach to evaluating an intervention. Adv Health Sci Educ Theory Pract. 1997; 2(3):221-236.

22. Troisi A, Massaroni P, Cuzzolaro M. Early separation anxiety and adult attachment style in women with eating disorders. Br J Clin Psychol. 2005;44(1):89-97.

23. Hinrichsen $H$, Wright $F$, Waller G, Meyer C. Social anxiety and coping strategies in the eating disorders. Eat Behav. 2003;482:117-126.

24. Zaitsoff SL, Geller J, Srikameswaran S. Silencing the self and supressed anger: relationship to eating disorder symptoms in adolescent females. Eur Eat Disord Rev. 2002;10(1):51-60.

25. Mack DE, Strong HA, Kowalski KC, Crocker PRE. Self-presentational motives in eating disordered behavior: a known groups difference approach. Eat Behav. 2007;8(1):98-105.

26. McGee BJ, Hewitt PL, Sherry SB, Parkin M, Flett GL. Perfectionistic self-presentation, body image and eating disorder symptoms. Body Image. 2005;2(1)29-40.

27. Saukko P. A critical discussion of normativity in discourses on eating disorders. In: Malson H, Burns M, editors. Critical Feminist Approaches. New York: Routledge/Taylor \& Francis Group; 2009:63-73.

28. Steiner-Adair C. The body politic: normal female adolescent development and the development of eating disorders. J Am Acad Psychoanal. 1986;14(1):95-114. 
29. Barnard VL, Graham-Berman SA. Can women cope? A gender analysis of Theories of Coping with Stress. In: Anselmi DL, Law AL, editors. Questions of Gender. Perspectives and Paradoxes. Boston, Mass: McGraw-Hill; 1998:702-712.

30. Ghaderi A, Scott B. Coping in dieting and eating disorders: a populationbased study. J Nerv Ment Dis. 2000;185(5):273-279.

31. Troop NA, Holbrey A, Treasure J. Stress, coping, and crisis support in eating disorders. Int J Eat Disord. 1998;24:157-166.

32. Lazarus RS. Coping theory and research: past, present, and future. Psychosom Med. 1993;55(3):234-247.

33. Matschiner M, Murnen SK. Hyperfemininity and influence. Psychol Women Quarterly. 1999;23:631-642.

34. Smolak L, Murnen SK. Gender and eating problems. In: StriegelMoore RH, Smolak L, editors. Eating Disorders: Innovative Directions in Research and Practice. Washington DC: American Psychological Association; 2001:91-110.
35. Linehan MM. Cognitive-behavioural Treatment of Borderline Personality Disorder. New York: Guilford Press; 1993.

36. Swales MA, Heard HL. Dialectical Behaviour Therapy. London: Routledge; 2009.

37. Safer DL, Telch CF, Agras WS. Dialectical behaviour therapy for bulimia nervosa. Am J Psychiatry. 2001;158:632-634.

38. Telch CF, Agras WS, Linehan MM. Dialectical behaviour therapy for binge eating disorder. J Consult Clin Psychol. 2001;69:1061-1065.

39. Polit DF, Beck CT. Nursing Research: Principles and Methods. 7th ed. Philadelphia: Lippincott Williams \& Wilkins; 2004.

40. Huon G, Strong K. The initiation and maintenance of dieting: structural models for large-scale longitudinal investigations. Int $J$ Eat Disord. 1998;23(4):361-369.

\section{Publish your work in this journal}

The Journal of Multidisciplinary Healthcare is an international, peerreviewed open-access journal that aims to represent and publish research in healthcare areas delivered by practitioners of different disciplines. This includes studies and reviews conducted by multidisciplinary teams as well as research which evaluates the results or conduct of such teams or healthcare processes in general. The journal covers a wide range of areas and welcomes submission from practitioners at all levels, from all over the world. The manuscript management system is completely online and includes a very quick and fair peer-review system. Visit http://www.dovepress.com/testimonials.php to read real quotes from published authors. 